\title{
Chronic exposure to particulate matter and risk of cardiovascular mortality: cohort study from Taiwan
}

\author{
Eva Tseng ${ }^{1}$, Wen-Chao Ho ${ }^{2}$, Meng-Hung Lin², Tsun-Jen Cheng ${ }^{3}$, Pau-Chung Chen ${ }^{3}$ and Hsien-Ho Lin ${ }^{*}$
}

\begin{abstract}
Background: Evidence on the association between long-term exposure to air pollution and cardiovascular mortality is limited in Asian populations.

Methods: We conducted a cohort study on the association between fine particulate matter $\left(\mathrm{PM}_{2.5}\right)$ and cardiovascular mortality using 43,227 individuals in a civil servants health service in Taiwan. Each participant was assigned an exposure level of particulate matter based on their district of residence using air pollution data collected by the Taiwan Environmental Protection Agency and with modeling using geographic information systems. The participants were followed up from 1989 to 2008 and the vital status was ascertained from death records. Cox regression models were used to adjust for confounding factors.
\end{abstract}

Results: The district-level average of $\mathrm{PM}_{2.5}$ ranged from 22.8 to $32.9 \mu \mathrm{g} / \mathrm{m}^{3}$ in the study area. After a median follow-up of 18 years, 1992 deaths from all causes including 230 cardiovascular deaths occurred. After adjustment for potential confounders, $\mathrm{PM}_{2.5}$ levels were not significantly associated with mortality from cardiovascular disease [Hazard Ratio (HR) 0.80; 95 \% Confidence Interval (Cl), 0.43 to 1.50 per $10 \mu \mathrm{g} / \mathrm{m}^{3}$ increase in $\mathrm{PM}_{2.5}$ ] or all causes (HR 0.92; $95 \% \mathrm{Cl}, 0.72$ to 1.17 per $10 \mu \mathrm{g} / \mathrm{m}^{3}$ increase in $\mathrm{PM}_{2.5}$. The results were similar when the analysis was restricted to the urban areas and when the $\mathrm{PM}_{2.5}$ measurement was changed from the period average (2000-2008) to annual average.

Discussion: Our findings are different from those in prior cohort studies conducted in Asia where ambient air pollutionwas associated with an increased risk of cardiovascular mortality. The high background level of air pollutionin our study area and the small number of event cases limited the power of this study.

Conclusions: In this population-based cohort study in Taiwan, we found no evidence of increased risk for all-cause or cardiovascular mortality with long-term exposure to $\mathrm{PM}_{2.5}$.

Keywords: Air pollution, Particulate matter, Cardiovascular mortality, Total mortality, Cohort studies

\section{Background}

Substantial research has been performed examining the adverse health effects of air pollution, specifically fine particulate matter with a diameter of $2.5 \mu \mathrm{m}$ or less $\left(\mathrm{PM}_{2.5}\right)$, which is primarily produced from the combustion of fossil fuels. The size of these fine particles allows them to be deposited deep down in the alveoli of the lung, resulting in prothrombotic states, endothelial dysfunction, progression of atherosclerosis, and increased systemic oxidative stress [1, 2]. PM has been established as a trigger of cardiovascular events

\footnotetext{
* Correspondence: hsienho@ntu.edu.tw

${ }^{4}$ Institute of Epidemiology and Preventive Medicine, National Taiwan University, 17 Xu-Zhou Road, Rm706, Taipei 100, Taiwan

Full list of author information is available at the end of the article
}

occurring within hours to days after exposure [3]. Moreover, studies have shown that extended exposure to fine particulate matter is an important predictor of mortality for cardiopulmonary disease [4-6]. A meta-analysis concluded that there was a $6.2 \%$ (95\% CI, 4.1 to $8.4 \%$ ) increased risk of all-cause mortality per $10 \mu \mathrm{g} / \mathrm{m}^{3}$ increase in $\mathrm{PM}_{2.5}$ exposure and $10.6 \%$ (95\% CI, 5.4 to $16.0 \%$ ) increased risk of cardiovascular mortality per $10 \mu \mathrm{g} / \mathrm{m}^{3}$ increase in $\mathrm{PM}_{2.5}$ [7]. The 2010 review by the American Heart Association writing group concluded that $\mathrm{PM}_{2.5}$ exposure is a "modifiable factor contributing to cardiovascular morbidity and mortality" [3].

The generalizability of these studies, conducted primarily in North America and Europe, to Asia is less known. Compared to Western countries, Asian countries 
have higher air pollution levels with different emission sources. Higher population density coupled with increasing urbanization mean that city residents in Asia have a greater exposure to air pollution than their counterparts in Western countries. Additionally, East Asian countries tend to have a lower coronary heart disease mortality but higher stroke mortality compared to Western countries [8].

Despite increasing public health interest in the effects of air pollution, attempts to provide a comprehensive global risk assessment have been limited in generalizability due to the small number of long-term cohort studies conducted in Asia. The majority of studies conducted in Asian countries have focused on short-term PM exposure $[9,10]$. Few cohort studies from Asia, including those conducted in China, Japan, and Hong Kong, have studied the effects of long-term exposure to air pollution, with only one study focusing on $\mathrm{PM}_{2.5}$ [11-16]. Therefore, the estimates for the global burden of disease attributable to ambient air pollution relies heavily on studies from Western countries [17, 18].

Given the limited evidence on the health effects of long-term exposure to ambient air pollution in Asia, we conducted a retrospective cohort study to examine the association between $\mathrm{PM}_{2.5}$ and cardiovascular and allcause mortality in Taiwan, an Asian country with high levels of ambient air pollution.

\section{Methods}

\section{Study population}

The study population was derived from a cohort of 75,395 individuals who were civil service employees and teachers. These individuals underwent an annual physical examination at the Taipei Outpatient Service Center as part of the government employee insurance program from 1989 to $1992[19,20]$. Of the 75,395 individuals enrolled in the civil servants cohort, we excluded from analysis 28,002 people with missing data on personal identification number and cardiovascular risk factors. Additionally, we excluded 4166 individuals who resided outside of Greater Taipei Area, which is defined as the area including New Taipei City and Taipei City. Within the Greater Taipei Area, 29 districts were represented out of a total of 41 districts. After these exclusions, 43,227 subjects $(24,630$ males and 18,597 females) were included in the final study (Fig. 1). The number of subjects, total population size, and area of each district are presented in the Appendix (see

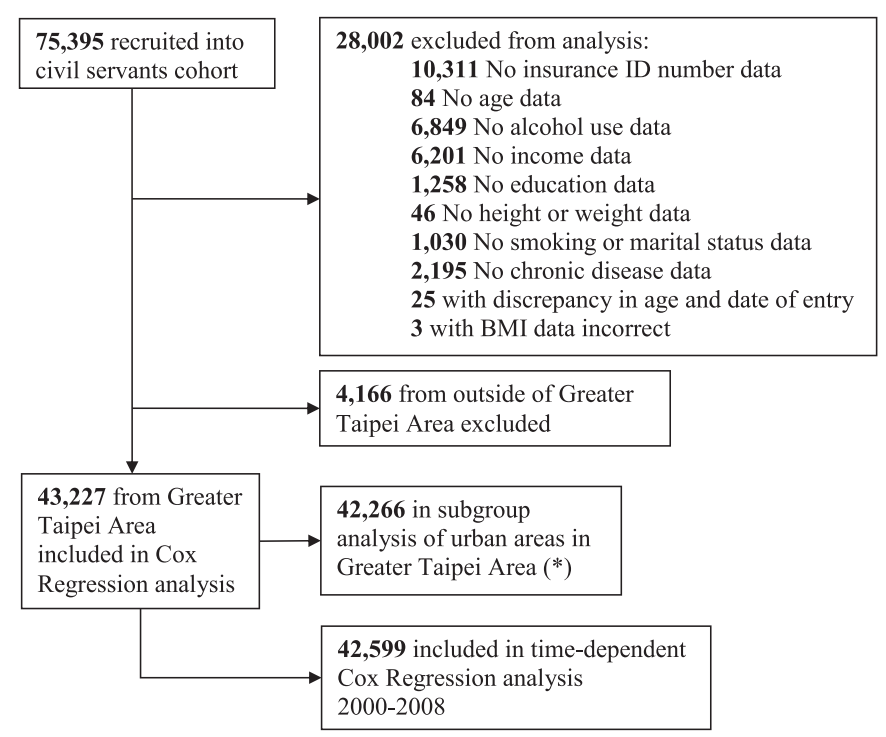

\begin{tabular}{|c|c|c|c|c|}
\hline Quintile 1 & Quintile 2 & Quintile 2 & Quintile 4 & Quintile 5 \\
\hline Sanzhi, Taipei & Linkou, Taipei & Shuangsi, Taipei & Daan, Taipei & Banciao, Taipei \\
\hline County & County & County & City* & County* \\
\hline Danshui, Taipei & Sizhi, Taipei & Wenshan, Taipei & Shulin, Taipei & Wanhua. Taipei \\
\hline County* & County* & City* & County & City* \\
\hline Beitou, Taipei & Wanfang, Taipei & Neihu, Taipei & Taishan, Taipei & Jhonghshan, \\
\hline City* & County & City* & County & Taipei City* \\
\hline Shimen, Taipei & Gongliao, Taipei & Yingge, Taipei & Shinyi, Taipei & Sanchong, Taipe \\
\hline County & County & County & City* & County* \\
\hline Shilin, Taipei & Sindian, Taipei & Sansia, Taipei & Yonghe, Taipei & Datong, Taipei \\
\hline \multirow[t]{3}{*}{ City* } & County* & County & County* & City* \\
\hline & Pingsi, Taipei & Jhonghe, Taipei & Jhongjheng, & Sinjhuang, \\
\hline & County & County* & Taipei City* & Taipei County* \\
\hline
\end{tabular}

Fig. 1 Flow diagram of exclusions and subgroup analyses of the civil servants cohort, Taiwan 
Additional file 1). The study cohort was followed from 1992 up until December 31st of 2008.

\section{Exposure assessment of ambient air pollution}

We obtained data on air pollution levels of $\mathrm{PM}_{2.5}$ from the Taiwan Environmental Protection Agency's Taiwan Air Quality Monitoring Network, which was established in 1990 and began collecting data in September 1993. The Air Quality Monitoring Network collects air pollution data from 76 stations in seven established districts. Mean pollution levels of $\mathrm{PM}_{2.5}$ were calculated over the period 2000-2008 and used as the primary exposure variable in the Cox regression analysis. Although $\mathrm{PM}_{2.5}$ measurements began in 1995, nationwide survey of $\mathrm{PM}_{2.5}$ was not implemented until August 2005 [21]. Therefore, the $\mathrm{PM}_{2.5}$ data for Greater Taipei City between 2000 and August 2005 was estimated using backward prediction based on historical trends. Specifically, we used data on other pollutants (PM with a diameter of $10 \mu \mathrm{m}$ or less, sulfur dioxide, nitric oxide, ozone and carbon monoxide) and temperature levels to estimate station-specific levels of $\mathrm{PM}_{2.5}$. We then used geographic information systems to estimate the $\mathrm{PM}_{2.5}$ level at the district level using the station-specific data and estimates for the period 2000-2008. We did not have air pollution estimates prior to 2000 available. Therefore, we used the estimates for 2000-2008 as a proxy for ambient air pollution during the period of cohort follow up from 1992 through 2008. Each participant was assigned an average $\mathrm{PM}_{2.5}$ level of exposure based on their district of residence which was determined by their phone number listed on the baseline questionnaire survey. For the time-dependent Cox regression analysis, we used the annual average PM2.5 levels from $2000-2008$ as the time-varying exposure.

\section{Measurement of covariates}

Information on known cardiovascular risk factors was obtained through self-administered questionnaires at baseline, including socioeconomic and demographic data such as marital status, income, education level, alcohol consumption, smoking, and selected baseline illnesses (hypertension and diabetes). Total cholesterol and triglyceride levels were determined by fasting venous blood sampling. The abbreviated Modification of Diet in Renal Disease Study formula was used to assess glomerular filtration rate (GFR).

\section{Ascertainment of mortality and cause of death}

The primary outcome of the study was cardiovascular and all-cause mortality. Vital status was determined by death records which are collected by the Taiwan Department of Health and have been computerized since 1971. The underlying cause of death was coded according to the International Classification of Disease $9^{\text {th }}$ revision (ICD-9) and $10^{\text {th }}$ revision (ICD-10). We used the following ICD codes to assess deaths from cardiovascular disease: ischemic heart disease (ICD-9 410-414, ICD-9 429.2, ICD-9 429.7, and ICD-10 I20-25) and cerebrovascular disease (ICD-9 430-438 and ICD-10 I60-69).

\section{Statistical analysis}

We used Cox proportional hazards model to estimate the hazard ratio and $95 \%$ confidence interval (CI) for all-cause and cardiovascular mortality due to ambient air pollution. The primary exposure variable was the average $\mathrm{PM}_{2.5}$ level over the period 2000-2008. The 29 districts in greater Taipei City that were represented in the cohort were ranked based on their average $\mathrm{PM}_{2.5}$ levels and then divided into quintiles with the reference group being the quintile with the lowest average. We decided to model particulate matter as a linear continuous variable and by quintiles because we wanted to assess if there may be a non-linear dose-response relationship between air pollution and cardiovascular mortality [17]. The ages of the subjects when they entered and exited the cohort were used to define the time variable for the Cox models. We adjusted for confounders by creating indicator variables for never, current or former smokers, habitual alcohol use, married or other, less then high school education, and body mass index (BMI) (with cutoffs at 20.1 and $27.5 \mathrm{~kg} / \mathrm{m}^{2}$ based on a study suggesting that the lowest risk of mortality for East Asians is in that range) [22]. We did not adjust for a history of cerebrovascular disease, heart disease, diabetes and hypertension because they are potential intermediaries between air pollution and the outcome of interest. Additionally, we did not adjust for lipid levels and renal function because there is some evidence suggesting that air pollution may be predictors of lipid disorders and decreased renal function [23, 24].

We performed additional analyses using time-dependent cox regression to examine the effect of sub-chronic exposure to $\mathrm{PM}_{2.5}$ over the period of 2000-2008. We were concerned that averaging the $\mathrm{PM}_{2.5}$ levels over time may have decreased the variability of exposure. Therefore, we examined time-varying exposures of one year in duration. Participants who died prior to 2000 were excluded and the remaining cohort was followed for events between 2000 and 2008.

Additionally, we conducted a subgroup analysis of the urban areas within greater Taipei City because we were concerned if there was confounding from area-level factors such as access to medical care, assuming that people living in less urban areas would have limited access to medical care. This subgroup included a total 42,266 individuals from 18 districts that were selected by the authors and deemed as "urban" areas (Fig. 1). Finally, we also examined the effect of other air pollutants including 
carbon monoxide $(\mathrm{CO})$, nitric oxide $(\mathrm{NO})$, nitrogen dioxide $\left(\mathrm{NO}_{2}\right)$, nitrogen oxides $\left(\mathrm{NO}_{\mathrm{X}}\right)$, sulfur dioxide $\left(\mathrm{SO}_{2}\right)$, and ozone $\left(\mathrm{O}_{3}\right)$ in several two-pollutant models. Statistical significance levels were determined by 2-sided $p$ value of 0.05 . All statistical analyses were carried out with SAS (Version 9.2, SAS Institute, Inc., Cary, NC).

\section{Standard protocol approvals, registrations, and} patient consent

All participants in the study gave written informed consent. This study was approved by the Institutional Review Board of National Taiwan University.

\section{Results}

The baseline characteristics of the cohort and air pollution measures are listed in Table 1 . The average $\mathrm{PM}_{2.5}$ levels across the five quintiles ranged from $25.8 \mu \mathrm{g} / \mathrm{m}^{3}$ to $32 \mu \mathrm{g} / \mathrm{m}^{3}$ (Fig. 2). The age and sex distributions were similar among the quintiles with women representing about $40-45 \%$ of the cohort. Only around $2 \%$ of participants had lower than high-school education. The majority of subjects had a monthly income between $\$ 30,000$ and $\$ 100,000$ New Taiwan dollars. Current smoking levels, habitual alcohol consumption, baseline total cholesterol, triglyceride and GFR measurements

Table 1 Baseline characteristics of the civil servants cohort according to quintiles of average PM $_{2.5}$ concentration during 1989-2008

\begin{tabular}{|c|c|c|c|c|c|}
\hline \multirow[t]{2}{*}{ Characteristic } & \multicolumn{5}{|l|}{ Quintile } \\
\hline & 1 & 2 & 3 & 4 & 5 \\
\hline No. of participants & 5,520 & 3,847 & 8,267 & 19,004 & 6,589 \\
\hline Range of average $\mathrm{PM}_{2.5}$ concentration, $\mu \mathrm{g} / \mathrm{m}^{3}$ & $22.8-27.2$ & $27.3-28.6$ & $28.7-30.0$ & $30.1-30.9$ & $31.5-32.9$ \\
\hline Mean $\mathrm{PM}_{2.5}$ in $\mu \mathrm{g} / \mathrm{m}^{3}$ (SD) & $25.8(1.4)$ & $28.3(0.4)$ & $29.6(0.4)$ & $30.4(0.3)$ & $32(0.4)$ \\
\hline Female sex (\%) & 47.3 & 38.7 & 39.2 & 44.5 & 42.6 \\
\hline Less than high-school education (\%) & 1.9 & 1.7 & 2.3 & 1.8 & 2.6 \\
\hline \multicolumn{6}{|l|}{ Marital status } \\
\hline Married (\%) & 45.7 & 41.1 & 39.3 & 39.2 & 37.9 \\
\hline Other (\%) & 54.3 & 58.9 & 60.7 & 60.8 & 62.1 \\
\hline \multicolumn{6}{|l|}{ Income in NT (\%) } \\
\hline$\leq \$ 30,000$ & 8.6 & 10.1 & 10.5 & 7.1 & 11.2 \\
\hline$\$ 30,000-60,000$ & 45.9 & 52.1 & 51.7 & 43 & 51.7 \\
\hline$\$ 60,000-100,000$ & 37.3 & 31.8 & 32.1 & 39.4 & 31.2 \\
\hline$>\$ 100,000$ & 8.2 & 6.1 & 5.8 & 10.5 & 5.9 \\
\hline Average age at recruitment in years (SD) & $40.6(10.4)$ & $40.6(10.7)$ & $40.4(10.4)$ & $42.5(10.5)$ & $39.7(10.8)$ \\
\hline \multicolumn{6}{|l|}{ Smokers (\%) } \\
\hline Never & 52.2 & 47.4 & 48.4 & 47.7 & 49.7 \\
\hline Former & 7.7 & 8 & 8.2 & 7.5 & 7 \\
\hline Current & 40.1 & 44.6 & 43.4 & 44.8 & 43.3 \\
\hline Habitual alcohol consumption (\%) & 72.4 & 75.3 & 73.7 & 74.6 & 73 \\
\hline Average body-mass index ${ }^{a}, \%$ & 22.7 & 23.1 & 23.9 & 22.8 & 22.8 \\
\hline$<20.1$ & 19 & 14.8 & 16.7 & 16.9 & 17.9 \\
\hline $20.1-27.5$ & 75.1 & 78.6 & 76.6 & 77.7 & 76 \\
\hline$>27.5$ & 5.9 & 6.7 & 6.7 & 5.4 & 6.1 \\
\hline Serum triglyceride level (mg/dL) & 113 & 116 & 116 & 113 & 117 \\
\hline Serum total cholesterol level (mg/dL) & 197 & 194 & 195 & 197 & 197 \\
\hline Diabetes mellitus (\%) & 2.2 & 1.8 & 1.7 & 2.1 & 1.7 \\
\hline Hypertension (\%) & 9 & 9.8 & 9.6 & 10.2 & 8.9 \\
\hline History of cerebrovascular disease (\%) & 0.4 & 0.3 & 0.4 & 0.3 & 0.3 \\
\hline History of heart disease (\%) & 4.4 & 5 & 5 & 5.2 & 4.5 \\
\hline Average GFR ${ }^{\mathrm{b}}\left(\mathrm{mL} / \mathrm{min} / 1.73 \mathrm{~m}^{2}\right)$ & 83 & 83 & 82.8 & 83.1 & 82.9 \\
\hline
\end{tabular}

GFR glomerular filtration rate, NT National Taiwan dollars, SD standard deviation

${ }^{a}$ Calculated as weight in kilograms divided by height in meters squared

${ }^{b}$ Calculated using the modification of diet in renal disease (MDRD) equation: eGFR (mL/min/1.73 m2) $=175 \times(\mathrm{Scr})-1 \cdot 154 \times($ Age $)-0 \cdot 203 \times(0 \cdot 742$ if female) 


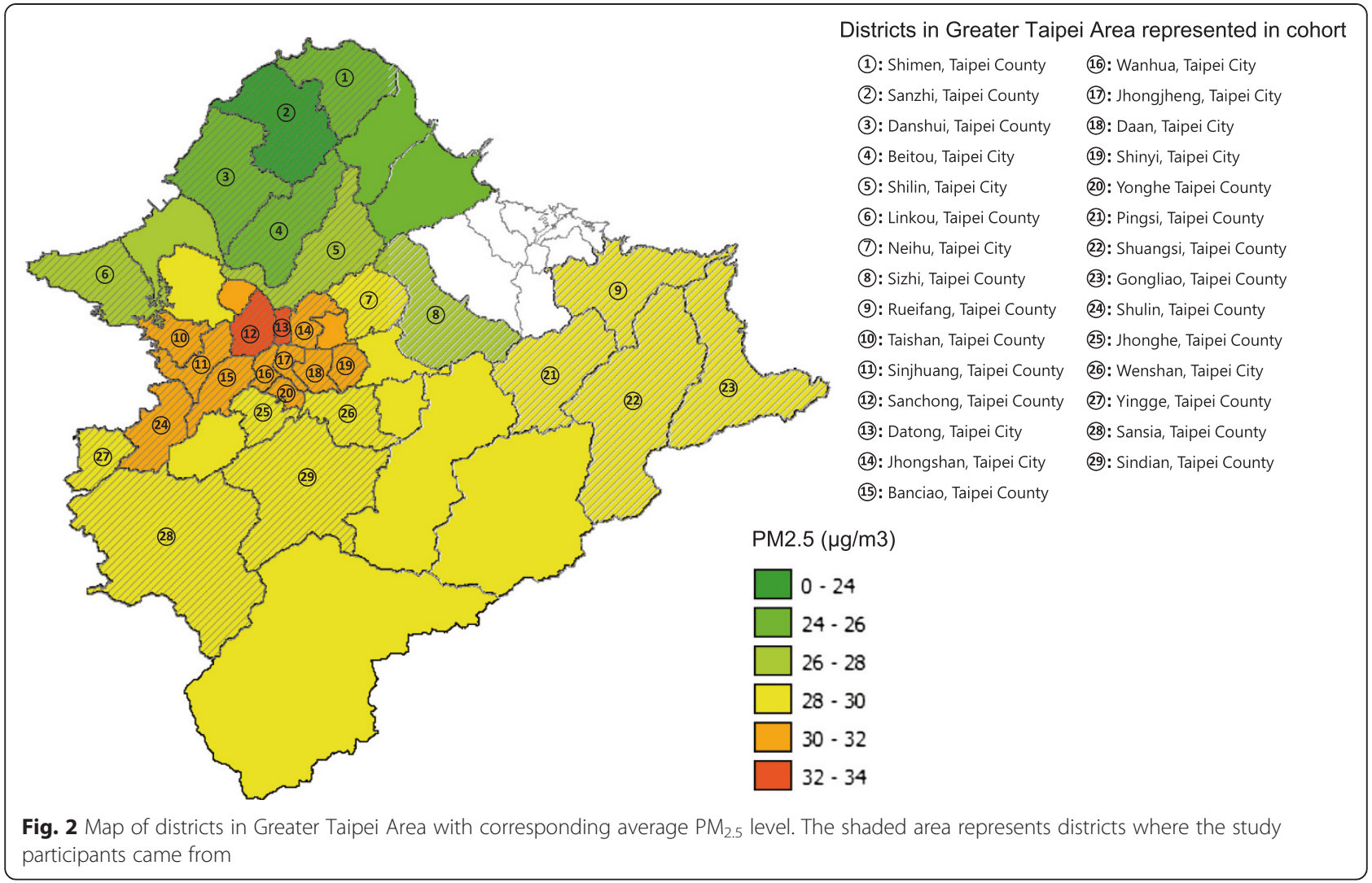

were also consistent across the quintiles. Baseline comorbid conditions were similar, with only about $2 \%$ of individuals reporting a history of diabetes, $0.3 \%$ reporting cerebrovascular disease, $9 \%$ reporting hypertension and around $5 \%$ reporting heart disease.

During the median 18-year follow-up, 280 deaths from cardiovascular disease (including 139 from ischemic heart disease and 141 from cerebrovascular disease) and 1992 deaths from all causes occurred. The crude mortality rate (all-cause and cardiovascular) did not reveal a strong dose-dependent pattern across quintiles of $\mathrm{PM}_{2.5}$ (Table 2). After adjusting for sex, age, education, marital status, income, smoking, alcohol consumption, and BMI, the level of $\mathrm{PM}_{2.5}$ was not significantly associated with all-cause (HR per $10 \mu \mathrm{g} / \mathrm{m}^{3}$ increase in $\mathrm{PM}_{2.5}$ : $0.92,95 \% \mathrm{CI}, 0.72$ to 1.17 ) and cardiovascular mortality (HR per $10 \mu \mathrm{g} / \mathrm{m}^{3}$ increase in $\mathrm{PM}_{2.5}: 0.80,95 \% \mathrm{CI}, 0.43$ to 1.50$)$. There appeared to be an inverse association between $\mathrm{PM}_{2.5}$ and mortality in the quintile and continuous-variable analysis, but the $p$ values for trend were not significant. The HRs did not change considerably in the crude versus multivariable-adjusted model (Model 1 and Model 2 in Table 2), suggesting that there was not much confounding present. Increased cardiovascular mortality was significantly associated with males (HR 2.42, 95 \% CI, 1.65 to 3.56) and increased
BMI $>27.5 \mathrm{~kg} / \mathrm{m}^{2}$ (HR 1.90, $95 \% \mathrm{CI}, 1.08$ to 3.35 ) and inversely associated with higher than high school education (HR 0.48, $95 \% \mathrm{CI}, 0.33$ to 0.71 ).

In the subgroup analysis of solely the urban areas within greater Taipei City (Fig. 1), results were similar to our prior analysis in that both crude and multivariable adjusted cardiovascular and all-cause mortality were not significantly associated with air pollution (data not shown). Given our concern that using the average $\mathrm{PM}_{2.5}$ level as the exposure variable may not be sensitive enough to show any association, we performed a time-dependent Cox regression analysis to investigate the sub-chronic effect of annual $\mathrm{PM}_{2.5}$ exposure. We found that the annual level of $\mathrm{PM}_{2.5}$ was not associated with cardiovascular mortality (HR 0.57, $95 \%$ CI, 0.28 to 1.18 per $10 \mu \mathrm{g} / \mathrm{m}^{3}$ increase in $\mathrm{PM}_{2.5}$ ). Finally, we investigated several other air pollutants including $\mathrm{CO}$, $\mathrm{NO}_{2}, \mathrm{NO}, \mathrm{NO}_{\mathrm{X}}, \mathrm{O}_{3}$ and $\mathrm{SO}_{2}$ to see if including this additional exposure would affect cardiovascular mortality. When these pollutants were analyzed individually, we did not find significant associations between the pollutants and cardiovascular mortality (Table 3). In the two-pollutant model in which we paired $\mathrm{PM}_{2.5}$ with one of these additional pollutants, the association between $\mathrm{PM}_{2.5}$ and cardiovascular mortality remained unchanged (Table 4). 
Table 2 Multivariate-adjusted hazard ratios for all-cause, CVD, IHD and cerebrovascular mortality, estimated from cox proportional-hazards model

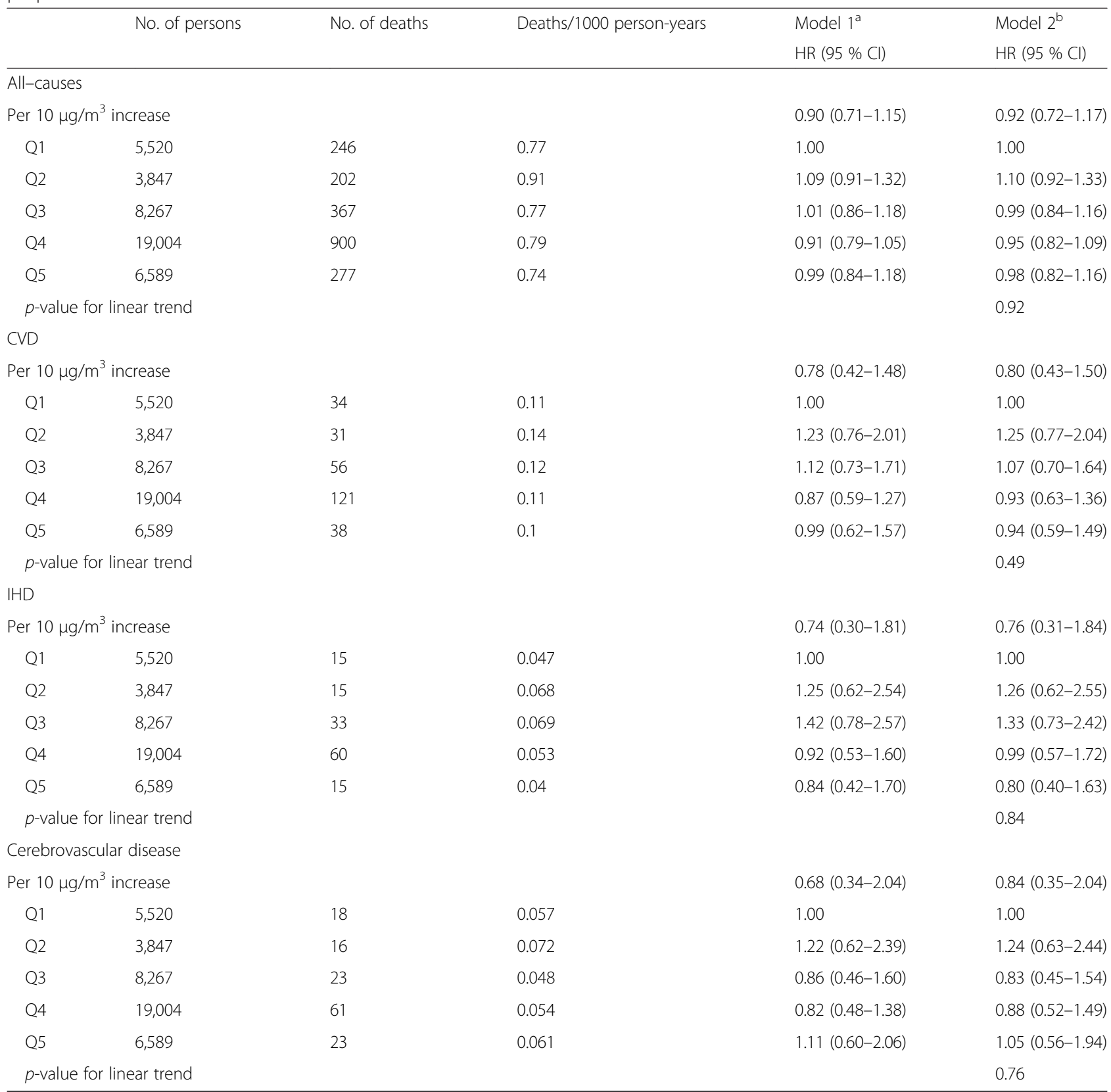

CVD cardiovascular disease (combines IHD and cerebrovascular disease), IHD ischemic heart disease, $\mathrm{Cl}$ confidence interval, $H R$ hazard ratio àodel 1: Adjusted for age

${ }^{\mathrm{b}}$ Model 2: Adjusted for age, sex, marital status, income, smoking, alcohol, BMI, and education

\section{Discussion}

Although there have been many epidemiologic studies in Asia assessing the health effects of short-term air pollution exposure, our study represents one of only a few cohort studies examining the association between long-term exposure to $\mathrm{PM}_{2.5}$ and cardiovascular mortality in Asia. After extensive adjustment for confounding factors, we did not observe an association between long-term exposure to particulate air pollution and cardiovascular and all-cause mortality in our study population.

Our findings are different from those in prior cohort studies conducted in Asia. Two cohort studies, one conducted in Shenyang and the other in 4 cities in Northern China, found that both all-cause and cardiovascular mortality were associated with increasing $\mathrm{PM}_{10}$ levels $[11,14]$. Similar results were found in another prospective cohort 
Table 3 Multivariable-adjusted cardiovascular mortality-rate ratios for other pollutants estimated from Cox proportional-hazards model

\begin{tabular}{lll}
\hline Pollutant & $\begin{array}{l}\text { Crude } \\
\mathrm{HR}(95 \% \mathrm{Cl})\end{array}$ & $\begin{array}{l}\text { Multivariable adjusted } \\
\mathrm{HR}(95 \% \mathrm{Cl})\end{array}$ \\
\hline $\mathrm{CO}(\mathrm{ppm})$ & $1.43(0.48-4.22)$ & $1.57(0.55-4.50)$ \\
$\mathrm{NO}(\mathrm{ppb})$ & $1.02(0.97-1.06)$ & $1.02(0.98-1.07)$ \\
$\mathrm{NO}_{2}(\mathrm{ppb})$ & $0.99(0.95-.103)$ & $0.99(0.95-1.04)$ \\
$\mathrm{NO}_{x}(\mathrm{ppb})$ & $1.00(0.98-1.02)$ & $1.00(0.98-1.03)$ \\
$\mathrm{O}_{3}(\mathrm{ppb})$ & $1.01(0.97-1.06)$ & $1.00(0.96-1.05)$ \\
$\mathrm{SO}_{2}(\mathrm{ppb})$ & $0.99(0.72-1.37)$ & $0.91(0.67-1.25)$ \\
\hline $\mathrm{CO}^{\mathrm{cabon}}$ & $\mathrm{m}$ &
\end{tabular}

$\mathrm{CO}$ carbon monoxide, $\mathrm{NO}$ nitric oxide, $\mathrm{NO}_{2}$ nitrogen dioxide, $\mathrm{NO}_{x}$ nitrogen oxides, $\mathrm{SO}_{2}$ sulfur dioxide, $\mathrm{O}_{3}$ ozone, $\mathrm{Cl}$ confidence interval, $\mathrm{HR}$ hazard ratio ${ }^{a}$ Adjusted for age, sex, marital status, income, smoking, alcohol, BMI, and education

study conducted in urban areas across China [12]. Another Chinese cohort study demonstrated a significant association between cardiovascular mortality and exposure to total suspended particles, $\mathrm{SO}_{2}$ and $\mathrm{NO}$ [16]. Finally, a recent cohort study conducted in Hong Kong assessed the long-term effects of $\mathrm{PM}_{2.5}$ exposure, which was estimated using U.S. NASA satellite data, and found a significant association with both all-cause and cardiovascular mortality [13].

Our results may vary from other studies because of the limited range in air pollution exposure within our cohort, which was conducted in the Greater Taipei Area. Several studies conducted within cities, such as the Vancouver and Ontario cohorts, have found similar null results suggesting that within city studies may not be comparable with between-city studies given limited spatial variability in $\mathrm{PM}_{2.5}$ [25-28]. In the Netherlands cohort study, $\mathrm{PM}_{2.5}$ exposure was limited in range similar to our study, and the authors did not find an association between $\mathrm{PM}_{2.5}$ and all-cause or cardiovascular mortality [28]. In the ACS intra-urban analysis of the New York City region, $\mathrm{PM}_{2.5}$ was also not associated with all-cause mortality [26]. Therefore, if we had compared our cohort from the Greater Taipei Area with other cities in Taiwan, our results may be different.
Another possibility for our negative result is confounding by neighborhood socioeconomic status, since cardiovascular mortality tends to be higher in rural areas (with lower air pollution) than in urban areas (with higher air pollution). However, when we restricted our analysis to urban districts, the association between $\mathrm{PM}_{2.5}$ and all-cause and CVD mortality remained unchanged. In addition, the difference between our study population and those in previously published studies should be noted. For example, the Harvard Six Cities Study population had a higher percentage of smokers (combining former and current smokers) and lower education levels, and many of the participants were exposed to dust or fumes at their job. In contrast, our study population only includes civil servants who have a high education level, steady income and likely no occupational exposure to dust or fumes. Therefore, their stable socioeconomic status may confer them less vulnerability to air pollution as suggested by prior published studies which argue that people with a high socioeconomic status and healthier lifestyles are less susceptible to the cardiovascular effects of air pollution [29].

We found a non-significant inverse trend between particulate matter and cardiovascular mortality. Our results are similar to the NIPPON DATA80 Japanese cohort study which found an inverse association between cardiovascular mortality and PM although their findings were statistically significant [15]. In this cohort study of 7250 individuals from 300 randomly selected districts in Japan, the authors found that adjusted HRs for cardiovascular mortality tended to decrease per $10 \mu \mathrm{g} / \mathrm{m}^{3}$ increase in PM (HR 0.90, 95 \% CI, 0.81 to 1.00). This inverse trend was also demonstrated in the Netherlands cohort in their case-cohort analysis after extensive adjustment for confounders, although the trend was not statistically significant [28].

The strengths of our study include having 20 years of prospective follow-up of a large cohort. We were able to adjust for confounders including cardiovascular risk factors like smoking and individual socioeconomic variables like income and education. We did several subsequent analyses including time-dependent cox regression analysis to see if sub-chronic exposure to $\mathrm{PM}_{2.5}$ would be a

Table 4 Multivariable-adjusted cardiovascular mortality-rate ratios for $\mathrm{PM}_{2.5}$ after adjusting for other pollutants

\begin{tabular}{|c|c|c|c|c|c|c|c|}
\hline Quintile & $\begin{array}{l}\mathrm{PM}_{2.5} \\
\mathrm{HR}^{\mathrm{a}}(95 \% \mathrm{Cl})\end{array}$ & $\begin{array}{l}\mathrm{PM}_{2.5}+\mathrm{CO} \\
\mathrm{HR}^{\mathrm{a}}(95 \% \mathrm{Cl})\end{array}$ & $\begin{array}{l}\mathrm{PM}_{2.5}+\mathrm{NO}_{2} \\
\mathrm{HR}^{\mathrm{a}}(95 \% \mathrm{Cl})\end{array}$ & $\begin{array}{l}\mathrm{PM}_{2.5}+\mathrm{NO} \\
\mathrm{HR}^{\mathrm{a}}(95 \% \mathrm{Cl})\end{array}$ & $\begin{array}{l}\mathrm{PM}_{2.5}+\mathrm{NO}_{x} \\
\mathrm{HR}^{\mathrm{a}}(95 \% \mathrm{Cl})\end{array}$ & $\begin{array}{l}\mathrm{PM}_{2.5}+\mathrm{O}_{3} \\
\mathrm{HR}^{\mathrm{a}}(95 \% \mathrm{Cl})\end{array}$ & $\begin{array}{l}\mathrm{PM}_{2.5}+\mathrm{SO}_{2} \\
\mathrm{HR}^{\mathrm{a}}(95 \% \mathrm{Cl})\end{array}$ \\
\hline 1 & 1.00 (reference) & 1.00 (reference) & 1.00 (reference) & 1.00 (reference) & 1.00 (reference) & 1.00 (reference) & 1.00 \\
\hline 2 & $1.25(0.77-2.04)$ & $1.20(0.74-1.96)$ & $1.05(0.59-1.89)$ & $1.37(0.83-2.24)$ & $1.17(0.72-1.91)$ & $0.99(0.48-2.04)$ & $1.32(0.76-2.29)$ \\
\hline 3 & $1.07(0.70-1.64)$ & $0.88(0.56-1.38)$ & $0.82(0.43-1.59)$ & $1.02(0.66-1.56)$ & $0.86(0.54-1.38)$ & $0.80(0.36-1.76)$ & $1.13(0.70-1.89)$ \\
\hline 4 & 36) & 07) & 44) & 7) & 0. & 0.6 & 0.9 \\
\hline 5 & $0.94(0.59-1.49)$ & $0.60(0.33-1.09)$ & $0.63(0.25-1.57)$ & $0.71(0.42-1.20)$ & $0.60(0.31-1.14)$ & $0.66(0.26-1.67)$ & $1.04(0.52-2.07)$ \\
\hline
\end{tabular}

$\mathrm{CO}$ carbon monoxide, $\mathrm{NO}$ nitric oxide, $\mathrm{NO}_{2}$ nitrogen dioxide, $\mathrm{NO}_{X}$ nitrogen oxides, $\mathrm{SO}_{2}$ sulfur dioxide, $\mathrm{O}_{3}$ ozone, $\mathrm{Cl}$ confidence interval, $\mathrm{HR}$ hazard ratio

${ }^{a}$ Adjusted for age, sex, marital status, income, smoking, alcohol, BMI, and education 
more sensitive measure of the exposure variability. We also examined the effect of other pollutants on the association between $\mathrm{PM}_{2.5}$ and $\mathrm{CVD}$ mortality. Evidence shows that these pollutants may have independent adverse effects on cardiovascular risk [8].

There are several limitations to our study. First, a major limitation was the lack of power due to the small number of event cases. This may in part be due to our use of ICD codes to determine the cause of death which can potentially lead to the underreporting of deaths due to cardiovascular disease and underestimate the effects. Second, studies conducted in Asia that found a positive association between cardiovascular mortality and PM defined cardiovascular deaths much more broadly than we did by including a wider range of ICD codes which could have led to a significant association $[9,12,13]$. Third, since our study is confined to the Taipei metropolitan basin, there was limited variability in $\mathrm{PM}_{2.5}$ exposure which may have restricted our ability to detect a significant association. Fourth, we used only the participant's phone number to assign them to a residential district and did not account for the possibility that participants moved during the study. Additionally, the air pollution data we used was partially obtained by backward prediction. Thus, both limitations could have led to exposure misclassification. Finally, we adjusted for personal characteristics only at baseline.

\section{Conclusions}

In this large population of civil servants from an Asian city, we did not find an increased risk of cardiovascular mortality with long-term exposure to fine particulate matter. Our findings were limited due to the small number of event cases and spatial variability in $\mathrm{PM}_{2.5}$. Nevertheless, given the paucity of data in Asia, we believe our study adds further knowledge to the current body of literature and highlights the need for more cohort studies to accurately estimate the effects of long-term air pollution on mortality in Asia.

\section{Additional file}

Additional file 1: Population size, area and cohort representation by districts in the Greater Taipei Area, Taiwan. (XLSX $10 \mathrm{~kb}$ )

\begin{abstract}
Abbreviations
BMI: Body mass index; CO: Carbon monoxide; CVD: Cardiovascular and cerebrovascular disease; GFR: Glomerular filtration rate; ICD: International classification of disease; IHD: Ischemic heart disease; $\mathrm{NO}_{2}$ : Nitrogen dioxide; NO: Nitric oxide; $\mathrm{NO}_{x}$ : Nitrogen oxides; NT: National Taiwan dollars; $\mathrm{O}_{3}$ : Ozone; $\mathrm{PM}_{2.5}$ : Particulate matter with a diameter of $2.5 \mu \mathrm{m}$ or less; $\mathrm{PM}_{10}$ : Particulate matter with a diameter of $10 \mu \mathrm{m}$ or less; $\mathrm{SO}_{2}$ : Sulfur dioxide.
\end{abstract}

\section{Competing interests}

The authors declare that they have no competing interests.

\section{Authors' contributions}

ET participated in the design of the study, performed statistical analysis, and drafted the manuscript. WCH participated in the study and helped with the statistical analysis. MHL helped with the statistical analysis. TJC participated in the study design. PCC participated in the study design. HH conceived of the study, and participated in its design and coordination and helped to draft the manuscript. All authors read and approved the final manuscript.

\section{Authors' information}

Not applicable.

\section{Availability of data and materials}

Not applicable.

\section{Acknowledgements}

The authors thank Dr. Chang-Fu Wu for providing estimates of air pollution for this study. Additionally, we thank Dr. Chien-Chou Chen for his help in creating the map for Fig. 2.

\section{Funding}

The study was funded by Taiwan Environmental Protection Agency and National Science Council (NSC-99-EPA-M-001-001).

\section{Author details}

'Division of General Internal Medicine, Johns Hopkins University, Baltimore, MD, USA. ${ }^{2}$ Department of Public Health, China Medical University, Taichung City, Taiwan. ${ }^{3}$ Institute of Occupational Medicine and Industrial Hygiene, National Taiwan University, Taipei, Taiwan. ${ }^{4}$ Institute of Epidemiology and Preventive Medicine, National Taiwan University, 17 Xu-Zhou Road, Rm706, Taipei 100, Taiwan.

Received: 5 April 2015 Accepted: 14 September 2015

Published online: 21 September 2015

\section{References}

1. Villeneueve PJ, Goldberg MS, Krewski D, Burnett RT, Chen Y. Fine particulate air pollution and all-cause mortality within the Harvard Six-Cities Study: variations in risk by period of exposure. Ann Epidemiol. 2002;12(8):568-76.

2. Peters A. Air quality and cardiovascular health: smoke and pollution matter. Circulation. 2009;120(11):924-7.

3. Brook RD, Rajagopalan S, Pope 3rd CA, Brook JR, Bhatnagar A, Diez-Roux AV, et al. Particulate matter air pollution and cardiovascular disease: an update to the scientific statement from the American Heart Association. Circulation. 2010;121(21):2331-78.

4. Dockery DW, Pope 3rd CA, Xu X, Spengler JD, Ware JH, Fay ME, et al. An association between air pollution and mortality in six U.S. cities. N Engl J Med. 1993;329(24):1753-9.

5. Pope 3rd CA, Thun MJ, Namboodiri MM, Dockery DW, Evans JS, Speizer FE, et al. Particulate air pollution as a predictor of mortality in a prospective study of U.S. adults. Am J Respir Crit Care Med. 1995;151:669-74.

6. Miller KA, Siscovick DS, Sheppard L, Shepherd K, Sullivan J, Anderson GL, et al. Long-term exposure to air pollution and incidence of cardiovascular events in women. N Engl J Med. 2007;356:511-3.

7. Hoek G, Krishnan RM, Beelen R, Peters A, Ostro B, Brunekreef B, et al. Long-term air pollution exposure and cardio-respiratory mortality: a review. Environ Health. 2013;12:43. doi:10.1186/1476-069X-12-43.

8. Ueshima H, Sekikawa A, Miura K, Turin TC, Takashima N, Kita Y, et al. Cardiovascular disease and risk factors in Asia: a selected review. Circulation. 2008;118(25):2702-9.

9. Gold DR, Mittleman MA. New insights into pollution and the cardiovascular system 2010 to 2012. Circulation. 2013;127(18):1903-13.

10. Su TC, Chen SY, Chang CC. Progress of ambient air pollution and cardiovascular disease research in Asia. Prog Cardiovasc Dis. 2011;53(5):369-78.

11. Zhang P, Dong G, Sun B, Zhang L, Chen X, Ma N, et al. Long-term exposure to ambient air pollution and mortality due to cardiovascular disease and cerebrovascular disease in Shenyang, China. PLoS One. 2011;6(6):e20827.

12. Zhou M, Liu Y, Wang L, Kuang $X, X u X$, Kan H. Particulate air pollution and mortality in a cohort of Chinese men. Environ Pollut. 2014;186:1-6.

13. Wong CM, Lai HK, Tsang H, Thach TQ, Thomas GN, Lam KB, et al. Satellitebased estimates of long-term exposure to fine particles and association 
with mortality in elderly Hong Kong residents. Environ Health Perspect. 2015 Advance online publication. doi:10.1289/ehp.1408264.

14. Zhang LW, Chen X, Xue XD, Sun M, Han B, Li CP, et al. Long-term exposure to high particulate matter pollution and cardiovascular mortality: a 12-year cohort study in four cities in northern China. Environ Int. 2014;62:41-7.

15. Ueda K, Nagasawa SY, Nitta H, Katsuyuki M, Ueshima H. NIPPON DATA80 Research Group. Exposure to particulate matter and long-term risk of cardiovascular mortality in Japan: NIPPON DATA80. J Atheroscler Thromb. 2012;19(3):246-54

16. Cao J, Yang C, Li J, Chen R, Chen B, Gu D, et al. Association between long-term exposure to outdoor air pollution and mortality in China: a cohort study. J Hazard Mater. 2011;186(2-3):1594-600.

17. Burnett RT, Pope 3rd CA, Ezzati M, Olives C, Lim SS, Mehta S, et al. An integrated risk function for estimating the global burden of disease attributable to ambient fine particulate matter exposure. Environ Health Perspect. 2014;122(4):397-403.

18. Lim SS, Vos T, Flaxman AD, Danaei G, Shibuya K, Adair-Rohani H, et al. A comparative risk assessment of burden of disease and injury attributable to 67 risk factors and risk factor clusters in 21 regions, 1990-2010: a systematic analysis for the Global Burden of Disease Study 2010. Lancet. 2012;380(9859):2224-60.

19. Wen CP, Tsai SP, Chen CJ, Cheng TY. The mortality risks of smokers in Taiwan: Part I: cause-specific mortality. Prev Med. 2004;39(3):528-35.

20. Ho MS. A long-term follow-up study of chronic diseases among civi servants and teachers in Taiwan (The Project Report). Taipei: Institute of Biomedical Sciences, Academia Sinica; 1993.

21. Environmental Protection Administration: Taiwan Air Quality Monitoring Network. http:/ttagm.epa.gov.tw/tagm/en (2010). Accessed 1 Sept 2014.

22. Zheng W, McLerran DF, Rolland B, Zhang X, Inoue M, Matuso K, et al. Association between body-mass index and risk of death in more than 1 million Asians. N Engl J Med. 2011;364(8):719-29.

23. Chuang K, Yan YH, Cheng TJ. Effect of air pollution on blood pressure, blood lipids and blood sugar: a pollution-based approach. J Occup Environ Med. 2010;52(3):258-62.

24. Lue SH, Wellenius GA, Wilker EH, Mostofsky E, Mittleman MA. Residentia proximity to major roadways and renal function. J Epidemiol Community Health. 2013;67(8):629-34.

25. Jerrett M, Finkelstein MM, Brook JR, Arain MA, Kanaroglou P, Stieb DM, et al. A cohort study of traffic-related air pollution and mortality in Toronto, Ontario. Canada Environ Health Perspect. 2009;117(5):772-7.

26. Krewski D, Jerrett M, Burnett RT, Ma R, Hughes E, Shi Y, et al. Extended follow-up and spatial analysis of the American Cancer Society study linking particulate air pollution and mortality. Res Rep Health Eff Inst. 2009;140:5-114.

27. Gan WQ, Koehoorn M, Davies HW, Demers PA, Tamburic L, Brauer M. Long-term exposure to traffic-related air pollution and the risk of coronary heart disease hospitalization and mortality. Environ Health Perspect. 2011;119:501-7.

28. Beelen R, Hoek G, van den Brandt PA, Goldbohm RA, Fischer P, Schouten LJ, et al. Long-term effects of traffic-related air pollution on mortality in a Dutch cohort (NLCS-AIR study). Environ Health Perspect. 2008;116:196-202.

29. Puett RC, Hart JE, Suh H, Mittleman M, Laden F. Particulate matter exposures, mortality, and cardiovascular disease in the health professionals follow-up study. Environ Health Perspect. 2011;119(18):1130-5.

\section{Submit your next manuscript to BioMed Central and take full advantage of:}

- Convenient online submission

- Thorough peer review

- No space constraints or color figure charges

- Immediate publication on acceptance

- Inclusion in PubMed, CAS, Scopus and Google Scholar

- Research which is freely available for redistribution 